\title{
The Subject-In-Situ Generalization Revisited ${ }^{1}$ Artemis Alexiadou and Elena Anagnostopoulou February 2006
}

To appear in Hans-Martin Gärtner \& Uli Sauerland (eds) Proceedings of the Workshop on Interfaces + Recursion = Language? Mouton de Gruyter.

\section{Goal}

The goal of this paper is to re-examine the status of the condition in (1) proposed in Alexiadou and Anagnostopoulou (2001; henceforth A\&A 2001 ), in view of recent developments in syntactic theory.

(1) The subject-in-situ generalization (SSG)

By Spell-Out, vP can contain only one argument with a structural Case feature. ${ }^{2}$

We argue that (1) is a more general condition than previously recognized, and that the domain of its application is parametrized. More specifically, based on a comparison between Indo-European (IE) and Khoisan languages, we argue that (1) supports an interpretation of the EPP as a general principle, and not as a property of T. Viewed this way, the SSG is a condition that forces dislocation of arguments as a consequence of a constraint on Case checking.

\section{Background on the SSG}

We will begin the discussion by reviewing the evidence that led A\&A (2001) to formulate (1). More specifically, we will present a number of constructions where subjects and objects with structural Case are not allowed to both remain in their base position: one of them must leave the vP.

\footnotetext{
${ }^{1}$ A preliminary version of this paper was presented at the workshop on Interfaces + Recursion $=$ Language? The View from Syntax and Semantics held in Berlin, March 24, 2005. We would like to thank the audience and Winfried Lechner for comments and discussion.

${ }^{2}$ The original formulation is as follows:

(i) By Spell-Out VP can contain no more than one argument with an unchecked Case feature.
} 


\subsection{Motivating the SSG: Stylistic Inversion and Quotative Inversion}

As is well known, in French and English there is a transitivity restriction on subject inversion in constructions containing an expletive subject. While expletive constructions are well-formed with intransitive verbs (2a-3a), transitive expletive constructions are ungrammatical $(2 b-3 b)$ :

(2) a. il est arrive un homme

Vexpl-VS

expl is arrived a man

'There has arrived a man'

b. *il a lu un eleve le livre *expl-VSO

expl has read a student-NOM the book -ACC

(3) a. there arrived a man Vexpl-VS

b. *there finished somebody the assignment *expl-VSO

It is generally agreed upon that the inverted subjects remain in $\mathrm{vP}-$ internal positions (see Bobaljik \& Jonas 1996; Déprez 1991 and references therein). In these languages, there are constructions where the subject can remain vP-internal with transitive predicates. These constructions involve movement of the object to a position outside the vP. These are stylistic inversion in French and quotative inversion in English.

\subsubsection{Stylistic Inversion}

Stylistic Inversion (SI; see Kayne \& Pollock 1978; Déprez 1990; Collins \& Branigan 1997; Watanabe 1996, among many others) involves postposing of the subject in wh-questions, relative clauses and subjunctive sentential complements (see Déprez 1991: 48-49). We mainly discuss whenvironments here:

(4) a. Je me demande quand partira Marie

I wonder when will leave Mary

'I wonder when Mary will leave'

b. Les resultats que nous donnent ces experiences

the results that us give these experiments

SI is inapplicable when no wh-movement takes place:

(5)

*partira ton ami

will-leave your friend

'Your friend will leave' 
Déprez (1991) argues that in SI the subject remains vP-internal. Her arguments include combien extraction, stage vs. individual level subjects and floating quantifiers. We briefly review the latter argument here.

In French there are (roughly) two positions in which floating quantifiers surface: following a tensed verb or following an auxiliary. Sportiche (1988) has argued that floating quantifiers are stranded quantifiers which mark the original DP position of the subject.

(6) *Qu'ont tous fait les enfants?

what did the children all do

If postverbal subjects in SI do not undergo movement, then the distribution of stranded quantifiers is correctly predicted. The ungrammaticality of (6) is not expected under an analysis of SI in terms of rightward movement of the subject.

SI is disallowed when the vP contains a direct object, as shown in (7) (see Kayne \& Pollock 1978: 604, 1998; Valois \& Dupuis 1992; Collins \& Branigan 1997; Español-Echevarría; Pinto \& de Wind 1998, among others):

(7) *Je me demande quand acheteront les consommateurs les pommes I wonder when will-buy the consumers-NOM the appples-ACC

If, however, the direct object itself is either wh-extracted or cliticized SI becomes possible again:

(8) a. Que crois-tu que manquent un grand nombre d'etudiants? what believe-you that be-absent-from a great number of students

b. Tes cours, a quelle occasion les ont manques un your course at which occasion them-have been absent-from a grand nombre d'etudiants? great number of students

The object must either be moved out of the vP, as in (8), or surface as a PP, as in (9) (Collins \& Branigan 1997 citing Kayne 1972):

(9) ?Quand ecrira ton frere a sa petite amie? when will write your brother to his little friend 'When will your brother write to his girlfriend?' 
We thus conclude that in order for a subject to remain vP-internal in French, either the DP object must be moved outside the vP or the object must be realized as PP.

\subsubsection{Quotative Inversion}

Sentences with direct speech complements allow a kind of inversion called Quotative Inversion (QI) by Collins \& Branigan (1997) and Collins (1997):

$$
\text { "I am happy", said Mary }
$$

Collins \& Branigan point out that QI is in many respects similar to SI. As with SI, the subject remains in vP-internal position, and the evidence again comes from floated quantifiers. The ungrammaticality of floating quantifiers following the inverted subject in examples like (11c) provides evidence that the subject has not moved outside the $\mathrm{vP}$ (assuming again Sportiche 1988):

(11) a. "We must do this again", the guests all declared to Tony

b. "We must do this again", declared all the guests to Tony

c. * "We must do this again" declared the guests all to Tony

Similarly to SI, when the quote triggers inversion in sentences with transitive verbs containing an indirect object, the result is ungrammatical (12a) unless the indirect object is expressed as a PP (12b). No such conflict arises in the absence of inversion, as shown in (12c):

(12) a. * "What is the exchange rate?", asked Mary John

b. "What is the exchange rate?", asked Mary of John

c. "What is the exchange rate?", Mary asked John

Thus, QI displays similar characteristics as SI: The transitive subject can remain $\mathrm{vP}$-internally only if $\mathrm{vP}$ does not contain another nominal argument. A vP-internal subject is compatible with a vP-internal, co-argumental PP, though (see (12b)).

\subsection{The Universality of the SSG}

The above facts motivate the generalization in (13): 
(13) Subject-inversion with vP-internal subjects is prohibited in the presence of vP-internal DP objects.

(13) follows from the SSG, repeated below:

(1) By Spell-Out vP can contain only one argument with a structural Case feature

In A\&A (2001) we claim that the SSG applies universally. There is no language in which both the subject and the object with a structural Case feature can remain $\mathrm{vP}-\mathrm{internal}^{3}$ We substantiate this claim through a discussion of a number of word order patterns across languages. More specifically, we argue on the basis of Transitive Expletive Constructions (TECs) in Icelandic, VSO orders in Celtic and Arabic and VOS orders in Italian and Catalan that either the subject or the object or both are crosslinguistically parsed into a vP-external position. Sequences in which both arguments can be shown to remain vP-internal seem to be absent. We refer the reader to A\&A (2001) for a detailed discussion of these patterns.

\subsection{The SSG in the T-model: v-to-T raising and Case checking}

In A\&A (2001) we offer an analysis of the SSG which is formulated in a framework that assumes that (i) overt and covert operations are empirically distinguishable primitives, (ii) Case checking is the result of movement to a Case checking position (Spec,TP or Spec, $\mathrm{vP}$ ) and (iii) Case checking takes place overtly or covertly (Chomsky 1995). More specifically, we point out that the generalization captured by the SSG can be further decomposed into two parts:

(14) i. If two DP arguments are merged in the vP domain, at least one of them must externalise.

ii. If two arguments remain vP-internal, one of them must surface as a PP.

We suggest that the two clauses of (14) can be understood if the SSG derives from the Case constraint in (1'). According to (1'), the presence in the overt syntax of two arguments with an unchecked structural Case feature in the $\mathrm{vP}$ domain is prohibited.

${ }^{3}$ See section 3 below for discussion of some apparent counterexamples to the SSG which support A \& A's (2001) analysis. 
(1') By Spell-Out, vP can contain only one argument with an unchecked Case feature.

The two clauses in (14) describe two alternative strategies that can be employed to circumvent ( $\left.1^{\prime}\right)$ : One of the two arguments must leave the vP moving to (or through) its Case checking position ( $\mathrm{T}$ or $\mathrm{v}$, and from there it can move further to C; clause $i$ of 14), or, alternatively, one of the two arguments is a PP lacking a structural Case feature (clause ii of 14). In both situations there is only one argument with an unchecked Case feature in the vP domain, conforming with (1').

The next question we address in A\&A (2001) is what explains (1'). Our answer is to suggest that there is a link between v-to-T raising and the SSG. In configurations violating the SSG, $\mathrm{v}$ and $\mathrm{T}$ fall together either overtly (in French / Icelandic and for Fox \& Pesetsky 2004, Johnson 1991 also in English) or covertly (in a traditional Emonds/Pollock-style analysis of English). The Case-features of the arguments must be checked after v-to$\mathrm{T}$ raising takes place creating a complex head with two Case features as in (15):

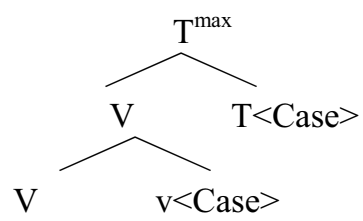

We propose that the complex head in (15), with two active Case features, is an illicit item. There are several reasons why this might be so. They all crucially rely on the assumption that $\mathrm{T}$ and $\mathrm{v}$ cannot directly enter into Case checking after head adjunction because they fail to c-command outside the non-terminal node dominating them. As a result, the Case features of $v$ and $\mathrm{T}$ must percolate up to T-max. This, however, can create several problems. One potential problem is that the complex head Tmax is not allowed to have more Case features than underived heads. For this reason, only one of the two Case features can be passed up to Tmax in (15). The other Case feature fails to enter into Case checking and the derivation crashes. Another possibility is that the presence of a Case feature on $\mathrm{T}$ blocks the Case feature of $\mathrm{v}$ from percolating up to the Tmax level. As a result, $\mathrm{v}$ cannot check the Case of the object, and the derivation crashes. A final potential problem is that (15) creates a fatal ambiguity configuration since the Case features on Tmax can be either those of T or those of $\mathrm{v}$. In this analysis, the 
SSG (1') results from the improper amalgamation of two Case-bearing heads $\mathrm{v}$ and $\mathrm{T}$, as stated in (16):

(16) $v$ and $T$ cannot both bear active Case features when they form a complex head.

As a consequence of (16), it is necessary that at least one Case feature be checked before the complex head is formed:

(17) $\mathrm{T}<$ Case $>$ or $\mathrm{v}<$ Case $>$ must be eliminated before the complex head is formed.

Intuitively, a local relationship between an argument and its Case-checking head must be established, which is destroyed by the formation of a complex head with two active Case features.

The clearest example of the effects of (15)/(16) is instantiated by the transitivity restriction in English/French. In these cases, the numeration contains a $\mathrm{v}$ and a $\mathrm{T}$ which both bear weak Case features that can be eliminated without phrasal pied-piping. The derivation proceeds as follows:

(18) (i) First, $v$ is merged, and the object does not raise overtly.

(ii) Then, $\mathrm{T}$ is merged.

(iii) The expletive is merged eliminating the EPP feature of $\mathrm{T}$.

(iv) $\mathrm{v}$ raises to $\mathrm{T}$ overtly or covertly, resulting in the formation of a complex head $\mathrm{T}^{\max }$ with two unchecked Case features.

As extensively argued for in A\&A (2001: 219-224), (15)/(16) does not arise in Icelandic TECs, Celtic and Arabic VSO and Romance VOS orders, i.e. whenever one of the two arguments (or both) undergo movement to a $\mathrm{vP}$ external position.

The analysis of the SSG in terms of (15)/(16) predicts that subjects and objects may remain vP-internal in languages lacking v-to-T raising, in apparent violation of the SSG. As will be seen in the next section, this prediction is indeed borne out.

\section{Challenges for SSG: Apparent exceptions}

A number of exceptions to the SSG have been noted in the literature. In this section, we will review these cases showing how they can be accommodated under A\&A's (2001) analysis. Crucially, whenever subjects and objects remain $\mathrm{vP}$ internal in apparent violation of the SSG, either (i) or 
(ii) holds: (i) The subject (or the object) is either Caseless or has its Case checked, and hence (1') is not violated. (ii) Raising of v-to-T fails to take place, and hence (16) is not violated.

\subsection{A\&A (2001): Greek, Spanish, Romanian.}

To begin with, A \& A (2001) discuss VSO orders in Greek, Spanish and Romanian, which appear to present counterexamples to the SSG. In the Greek example (19) both arguments remain vP internal, as is evidenced by the fact that they follow manner adverbs that have been argued to mark the left edge of the vP. Note that participles precede manner adverbs in Greek, a fact that has been analysed in terms of the proposal that they raise overtly to an aspectual head Asp above Voice where manner adverbs occur (see Alexiadou 1997):

\section{(19) an ehi idi diavasi [vP prosektika [o Janis} to vivlio] if has already read carefully the-John-NOM the book-ACC 'If John has already read the book carefully'

A\&A (2001) argue that such orders do not challenge the SSG, understood in terms of the Case checking constraint (1'), because the Case of the in situ subject is realized on the pronominal verbal agreement which has the status of a clitic and checks overtly its (phi and Case) features on $\mathrm{T}$ as a result of verb-raising (cf. Alexiadou \& Anagnostopoulou 1998). In this analysis, the inverted in situ subject does not have an unchecked structural Case feature, despite appearances to the contrary. We link the above mentioned property of Greek, Spanish and Romanian verbal subject agreement to the clitic doubling parameter which permits the formation of such feature-chains ${ }^{4}$ between clitics and in situ DP arguments in clitic doubling languages like Greek, Spanish and Romanian and prohibits them in non-clitic doubling languages like French, Italian and Catalan.

\subsection{Further exceptions to the SSG}

Some further counterexamples to the SSG are reported in the more recent work of Wurmbrand (2004), Carstens (2005) and Baker and Collins (2005).

\footnotetext{
${ }^{4}$ See Anagnostopoulou (2003) for a particular analysis of such feature chains. Based on locality considerations Anagnostopoulou argues that clitic doubling languages permit overt feature movement without phrasal pied piping.
} 
In what follows, we argue that these cases do not contradict the SSG, understood as either (1') or (16).

\subsubsection{German}

It has been argued that subjects and objects may both remain $\mathrm{vP}-$ internal in German (see e.g. Haider 1993, to appear; Fanselow 2001; Wurmbrand 2004 and others). Evidence for this comes from two sources. First, adverbial placement demonstrates that both arguments remain inside the vP:

(20) weil schon oft ein junger Hund einen Briefträger gebissen hat since already often a young dog a mailman bitten has 'Since a young dog has already often bitten a mailman'

Second, in contexts of vP-fronting, both arguments can be topicalized: ${ }^{5}$

(21) [Ein junger Hund einen Briefträger gebissen] hat hier schon oft a young dog a mailman bitten has here already often 'It has happened often here already that a young dog has bitten a mailman'

Wurmbrand (2004) notes that these examples present a potential problem for the SSG. We believe, however, that the problem is only apparent. There are two potential explanations for why German permits vP internal subjects and objects, both of which are compatible with A\&A's (2001) analysis: (a) One possibility is that German permits feature-chains between null clitics and in situ DP arguments qualifying essentially as a clitic doubling language (following Haider 1985; Fanselow 2001). Hence, there is no violation of the SSG understood as in (1'). (b) Alternatively, German lacks head-movement being a head-final language (Haider 1993, to appear). Hence, German lacks the formation of complex heads like (15) that would lead to a violation of (16).

\subsubsection{Kilega}

As discussed in Kinyalolo (1991) and Carstens (2005: 238-239), Kilega has transitive inversion constructions in which subjects and objects arguably remain in situ in violation of the SSG. Consider (22) (Carstens's 2005 ex.

\footnotetext{
${ }^{5}$ Examples (20) and (21) are taken from Wurmbrand (2004). Note that not all speakers judge (21) to be well-formed (Gereon Müller, p.c.).
} 
(34)), which displays locative inversion in a sentence containing an auxiliary and a main verb:

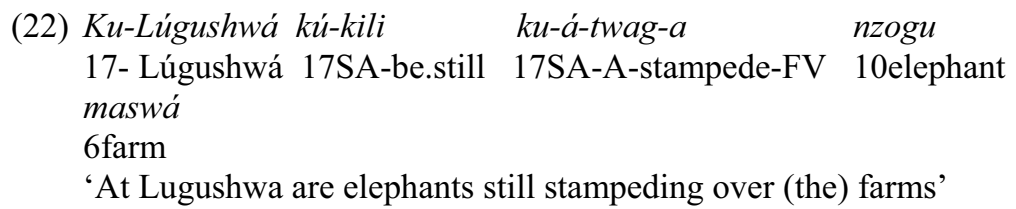

Carstens argues that (22) should be analysed as in (23) (raising of the locative omitted):

$$
\begin{aligned}
& \text { (23) } \text { [тр ku-T [AspP1 }_{\text {kili }} \text { Asp1 }_{\text {AspP2 }} \text { ku-á Asp2 } \quad \text { [MP twag-a Mood } \\
& \text { 17agr-(PRES) be.still 17agr-A stampeding } \\
& \text { [vP } \mathrm{SU} \mathrm{t}_{\mathrm{v}}\left[\mathrm{vv}_{\mathrm{v}} \mathrm{OB}\right. \text { ku Lúgushwá ]]]]]] } \\
& \text { elephants farm Loc- Lúgushwá }
\end{aligned}
$$

On the assumption that there is no V-raising beyond the suffixes in Kilega, $\mathrm{V}$-movement always terminates to a position below $\mathrm{T}$ in this language (as extensively argued for in Kinyalolo 2003 and Carstens 2005). In compound tenses like (22)/(23) (see Carstens 2005: 226-230) the main verb raises to a low MoodP, which contains the final vowel of Bantu verbs, and is preceded by an aspectual prefix projected under a low aspectual head Asp2. The aspectual auxiliary is in Asp1 while T hosts abstract Tense features (PRES in this example). The fact that both the subject and the object follow the main verb in (22) provides evidence that both arguments remain vP internal. ${ }^{6}$

As pointed out by Carstens (2005:239), lack of V-to-T movement in Kilega provides the key to an understanding of why inversion constructions do not violate the SSG. Under the assumption that the SSG results from the improper amalgamation of $\mathrm{v}+\mathrm{T}$ with active Case features, as proposed by A\&A (2001), the fact that no V-to-T movement takes place in Kilega can explain why this language has transitive inversion constructions with vPinternal arguments. The head (15) is never formed, and the constraint (16) does not arise.

\footnotetext{
${ }^{6}$ Note that the verb agrees with the moved locative phrase rather than the in situ subject in (22), as is always the case in Bantu constructions displaying inversion (see Baker 2003; Carstens 2005 for recent discussion).
} 


\subsubsection{Kinande.}

Baker \& Collins (2005: fn. 13) point out that Kinande constructions as in (24) could be taken to violate the SSG:
(24) Mo-ha-teta-sat-a
(*a-)mu-kali omo-soko
Aff-there-Neg/Past-dance-Fv
Aug-1-woman Loc.18-market
'There danced no woman in the market'

Example (24) features a vP-internal subject and a locative argument which is nominal and bears structural Case, as extensively discussed in Baker \& Collins (2005). It therefore looks as if (24) violates the SSG. This is only apparent, however, because the vP- internal subject in (24) lacks a structural Case feature, as Baker \& Collins (2005) argue. The crucial evidence for this comes from the observation that the subject is not allowed to bear the initial augment vowel in (24). The augment vowel occurs with all nominals that are interpreted as DPs in Kinande while in its absence nominals are interpreted as NPs. Under the assumption that structural Case is a feature of D, the obligatory absence of the augment in (24) signifies that the subject lacks Case. In turn, this explains why both nominal arguments remain vP internally. Thus, Kinande presents one more case where the SSG, understood as the Case constraint (1'), is not violated. ${ }^{7}$

\section{Expanding the SSG: object movement in linker constructions.}

Collins (2003) and Baker and Collins (2005) discuss a constraint which forces movement of one object out of the VP-domain in constructions involving two objects in the Khoisan languages Ju'hoansi and $\neq$ Hoan (Collins 2003; Baker and Collins 2005), and in Kinande (Niger-Congo; Baker and Collins 2005). The existence of this constraint, which is strongly reminiscent of the SSG, leads to the view that the SSG is more general than previously recognized and that the domain of its application is parametrized. The constraint in question is attested in constructions where a particle, called "linker" by Collins (2003) and Baker and Collins (2005), appears between the direct object and a secondary object or nominal adpositional phrase. Some examples illustrating the linker-construction in

\footnotetext{
${ }^{7}$ According to Baker and Collins (2005, fn. 5), the verb probably moves to Infl in Kinande, since subject-adverb-verb orders are not found in this language. Hence, the grammaticality of Kinande (24) cannot be attributed to the lack of v-to-T raising, unlike the Kilega example (22).
} 
Ju'hoansi are provided in (25). In (25a) the linker ko appears between the theme and a locative phrase, in (25b) between the theme and an instrument and in $(25 \mathrm{c})$ it occurs between the two objects of a double object construction, the beneficiary and the theme (from Collins 2003: 1-2):

\section{(25) a. Uto dchuun-a / Kaece ko n!ana n!ang car hit-TRANS |Kaece ko road in 'A car hit Kaece in the road' \\ b. Mi ba //ohm-a !aihn ko /'ai \\ My father chop-TRANS tree ko axe \\ 'My father chopped the tree with an axe' \\ c. Besa komm //'ama-/' an Oba ko tcisi \\ Besa EMPH buy-give Oba ko things \\ 'Besa bought Oba some things'}

In what follows, we will mainly concentrate on Ju'hoansi locative constructions, as discussed in Collins (2003), ${ }^{8}$ because they present particularly clear evidence that the SSG not only regulates the placement of subjects and objects in the vP domain but also regulates the placement of two objects in the VP domain.

To begin with, observe that in Ju'hoansi locative (and instrumental) constructions the particle $k o$ co-occurs with the transitivity suffix $-a$ (glossed TRANS in (25a) and (25b)). As will be seen immediately, the conditions under which $-a$ and $k o$ surface are closely related, though not identical. While the transitivity suffix $-a$ appears when a locative phrase follows a transitive and an intransitive verb, the particle $k o$ appears when a locative phrase follows a transitive verb but not when a locative phrase follows an intransitive verb. More specifically, the transitivity suffix $-a$ and the particle $k o$ are both disallowed with transitive verbs, as shown in (26), while they are both required when a locative phrase is added to transitive verbs, as shown in (25a) above.

\footnotetext{
${ }^{8}$ Baker and Collins (2005) re-interpret some of the facts discussed in Collins (2003; most notably, the A' extraction facts in Ju'hoansi illustrated in (34) and (35) below) in a way that obscures the similarity between the phenomena studied in A\&A (2001) and their linker counterparts. For this reason, we mainly focus on Collins's (2003) interpretation of the facts. Even though a full comparison between A\&A (2001), Collins (2003) and Baker and Collins (2005) is beyond the scope of the present paper, we highlight in fn. 10 below one crucial difference between Baker and Collins's (2005) approach and ours.
} 
(26) a. Uto dchuun- $\left({ }^{*} a\right) /$ Kaece

Car hit-TRANS |Kaece

'The car hit |Kaece'

b. *Uto dchuun-(a)/Kaece ko

Car hit-TRANS |Kaece ko

'The car hit |Kaece'

c. *Uto dchuun-(a) ko /Kaece

Car hit-TRANS ko |Kaece

'The car hit |Kaece'

On the other hand, when a locative phrase is added to an intransitive verb, $-a$ is required (see (27)) but $k o$ is ungrammatical (compare (28a) to (28b)):

(27) a. Ha ku $u$

3SG ASP go

'He was going'

b. Ha ku u-a Tjum!kui

3SG ASP go-TRANS Tjum!kui

'He was going to Tjum!kui'

(28) a. Lenakoh djxani-a tju n!ang

Lena PAST dance-TRANS house in

'Lena danced in the house'

b. *Lenakoh djxani-a ko tjun!ang

Lena PAST dance-TRANS ko house in

In order to account for the distribution of $-a$ in Ju'hoansi, Collins (2003) argues that locative phrases are nominal and have a Case feature to check. The transitivity suffix $-a$ is inserted to check the Case of locative phrases. This explains why $-a$ is added in transitive (25a) and intransitive (27b), (28a). In (25a) transitive v checks the Case of either DP/Kaece or PP $n$ !ana $n$ ! ang, and the transitivity suffix $-a$ checks the Case of the other argument, as shown in (29): 
(29)

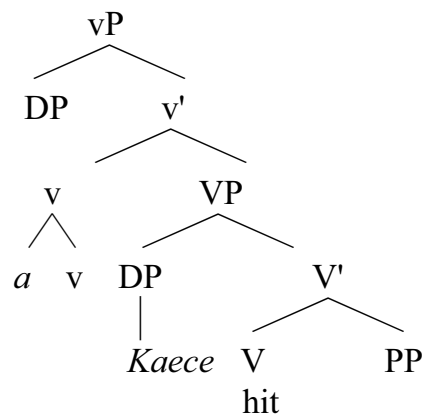

Similarly, in (27b) and (28a) $-a$ is added on an intransitive $\mathrm{v}$ (which lacks a Case feature) to check the Case feature of the nominal PPs Tjum!kui and tju n!ang, respectively.

The question that arises next concerns the distribution of $k o$, which is present in transitive constructions like (25a) and absent in intransitives like (27), (28). Note that the presence of $k o$ is obligatory in transitives. Example (30), which lacks $k o$, is ungrammatical:

\section{(30) *Uto dchuun-a/Kaece n!ana n!ang \\ car hit-TRANS |Kaece road in \\ 'A car hit Kaece in the road'}

In order to account for the obligatory presence of $k o$ in transitive constructions with a locative (such as (30)) and its obligatory absence in intransitive constructions with a locative (such as (28b)), Collins (2003: 1516) argues that $k o$ is a Last Resort mechanism. It is inserted to provide a landing site for movement in constructions that would otherwise violate a condition which he labels Multiple Case Condition (MCC):

(31) Multiple Case Condition

By Spell-Out, VP can contain no more than one argument with a (valued) undeleted Case feature.

In (29) above, the complex functional head [v $a$ v] has two sets of uninterpretable phi-features, one for $a$ and one for v. Even though two Agree relations can be established - Agree (v, DP) and Agree ( $a, \mathrm{PP})$ - there are two Case features internal to the VP that need to be deleted at Spell-Out. In order to avoid a violation of the MCC, $k o$ is merged providing a landing site for one of the two arguments, as schematized in (32): 
(32)

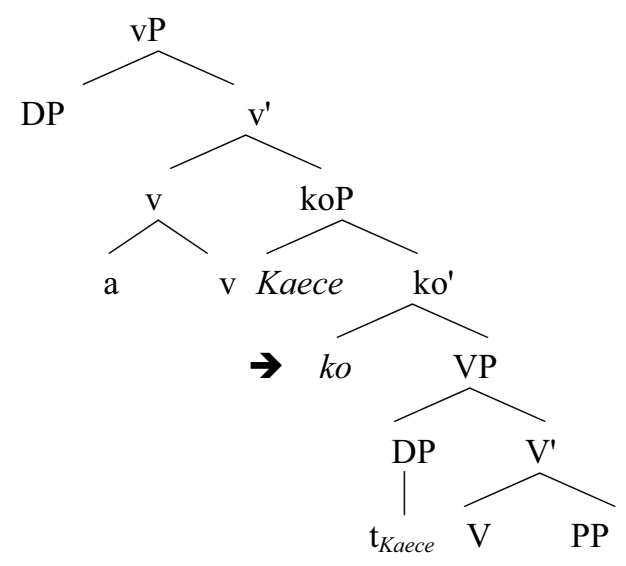

Being a Last Resort operation, $k o$-insertion is triggered only if a violation of the MCC would ensue, which explains why ko is obligatorily absent in intransitives.

In (25a), the DP Kaece leaves the VP, as depicted in (32). Movement of locative and instrumental PPs is also possible in Ju'hoansi, as shown by the examples (33) (see Collins 2003: 9):

\section{(33) a. Uto dchuun-a n!ana n!ang ko /Kaece car hit-TRANS road in ko |Kaece 'A car hit Kaece in the road'
b. Ha gu-a
//'aisi
3SG build-TRANS grass
ko tju \\ 'He built the house with grass'}

For the purposes of the MCC, it doesn't matter which argument moves out of the VP as long as one of them does. ${ }^{9}$

The MCC is a version or a close relative of the SSG. Just as the SSG forces movement of either the subject or the object out of the vP when both have structural Case, the MCC forces movement of either the direct object or the adpositional phrase out of the VP when both have structural Case.

\footnotetext{
${ }^{9}$ See Collins (2003) and Baker and Collins (2005) for further discussion of the constraints of movement of the lower argument in Ju'hoansi double object constructions and $\neq$ Hoan locative, instrumental and double object constructions, which follow from locality considerations.
} 
And, importantly, if one of the VP constituents is extracted by A'movement, the result is acceptable without ko, as shown in (34) and (35):

$$
\begin{aligned}
& \text { Kaece komm uto dchuun-a }\left({ }^{* k o}\right) \text { n! ama n!ang } \\
& \text { Kaece emph car hit-trans road in } \\
& \text { 'Kaece, the car hit in the road' } \\
& N \text { !ama n!ang komm uto dchuun-a }\left({ }^{*} k o\right) \text { Kaece } \\
& \text { road in emph car hit-trans Kaece } \\
& \text { 'In the road the car hit Kaece' }
\end{aligned}
$$

This pattern is strongly reminiscent of the conditions licensing Stylistic Inversion in French. (Recall that SI is possible when the object undergoes A' movement or cliticization as shown in (8), section 2.1.1. above.)

On the basis of the above discussion, we conclude that the SSG is a broader condition than initially assumed and that the domain of its application is subject to parametric variation. We distinguish between two types of SSG effects:

(i) The vP-type is attested in the languages discussed in A\&A (2001). Here the competing arguments are the subject and the object, which are not allowed to remain both vP-internal, as illustrated by the Icelandic example (36):

(36) *pað klaruðu [ ${ }_{v P}$ alveg margar mys ostinn] there finished completely many mice the cheese

(ii) The VP-Type is attested in the languages discussed in Collins (2003) and Baker and Collins (2005). ${ }^{10}$ Here the competing arguments are

${ }^{10}$ Baker and Collins (2005) redefine the MCC in a way that is less compatible with the SSG :

(i) The Multiple Case Constraint (revised) (their condition (35)).

By Spell-Out, if the VP complement of v contains a DP with a Case feature, then VP cannot contain any other nominal expression (includes augmentless NPs, semi-nominal locatives, and DPs with Case features)

The basic intuition behind the formulation in (i) is that if v checks the Case of a DP (with an unvalued Case feature) inside its VP complement, then it requires that no other potential Case bearing elements (such as NPs or locatives) are around internal to that VP to compete with it. The reason why Baker and Collins (2005) define the MCC in terms of potential (and not actual) Case bearing elements is because they argue that the MCC applies even when the VP contains locative adjuncts and augmentless NPs in Kinande which do not have a Case feature. This version of the MCC does not seem to us to be unifiable with the SSG for two 
the theme-object and the PP-nominal object, which are not allowed to remain both VP internal, as shown in (37).

\section{(37) *Uto dchuun-a ko Kaece n! ana n!ang car hit-TRANS ko Kaece road in 'A car hit Kaece in the road'}

Note, finally, that the configurations discussed by A\&A (2001) and Collins (2003) are formally very similar. In both cases we arrive at the formation of a complex head, which is argued to be an illicit object in A\&A (2001). The complex head (15), repeated below as (38), is created in vPtype SSG effects. The complex head (29), repeated below as (39), is created in VP-type SSG effects.

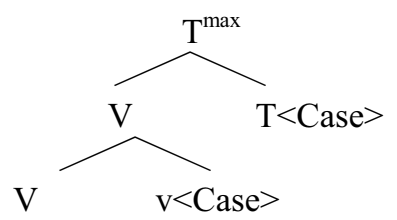

(39)

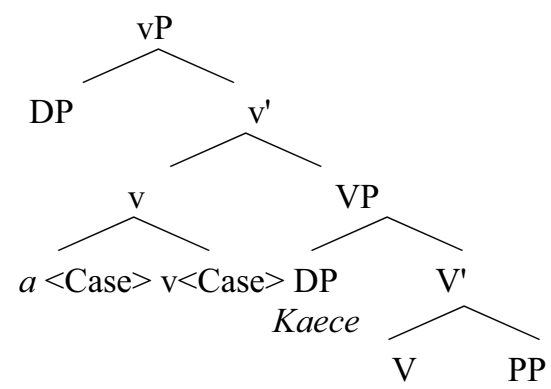

reasons at least: (i) A\&A's (2001) account of the SSG crucially relies on the assumption that both vP internal arguments require Case, and one of them cannot receive it after the formation of the complex head (15), which leads to a crashing derivation. (ii) As we saw in section 3.2.3. above, constructions with a vP internal subject and a locative nominal argument such as (24) are well-formed in Kinande, in apparent violation of the SSG, because, crucially, the vP- internal subject in (24) is augmentless and hence lacks a structural Case feature. Augmentless NPs in Kinande, however, still trigger the insertion of a linker to avoid a violation of the MCC, as stated in the revised MCC (i)/(35) above. 
The two configurations differ only in that the complex head in (38) is formed by v-raising, while the formation of a complex head is derived by suffixation of the transitive marker $a$ to $\mathrm{v}$ in (39).

\section{The SSG revisited}

\subsection{Generalized EPP and Case}

In the preceding sections we saw that a constraint prohibiting more than one arguments with an unchecked structural Case feature applies to distinct domains (vP or VP) forcing argument externalisation. Specifically:

(i) When the constraint under discussion targets the $\mathrm{vP}$ it derives the effects of the SSG discussed in A\&A (2001):

(1') The Subject-In-Situ Generalization (SSG)

By Spell-Out, vP can contain only one argument with an unchecked Case feature.

The SSG applies to subjects and objects and triggers externalisation in the domain above $\mathrm{v}$ (spec, TP or spec, $\mathrm{vP}$ ).

(ii) When the constraint targets the VP it derives the effects of the MCC (a version of the SSG) discussed in Collins (2003):

(31) Multiple Case Condition (MCC)

By Spell-Out, VP can contain no more than one argument with a (valued) undeleted Case feature.

The MCC applies to two objects and triggers externalisation in the domain above $k o$.

In view of the tight connection between $\left(1^{\prime}\right) /(31)$ and argument externalisation, the SSG/ MCC can, in turn, be seen as a constraint on multiple Case checking implementing EPP effects.

In recent literature, there are two different conceptions of the EPP. On one view, EPP is a condition on T or a feature on T. On another view, EPP is a general condition regulating argument movement to $\mathrm{V}$ or $\mathrm{T}$ (Generalized EPP; see Alexiadou \& Anagnostopoulou 1996, 1997 for an early proposal along these lines). As discussed in A\&A (2001), both versions of the EPP are empirically correct, capturing different sets of facts. In the SSG configurations identified and analysed by A\&A (2001) the EPP as a property of $\mathrm{T}$ is satisfied in four different ways summarized in (40): 
(40) Devices satisfying the EPP property of $T$

(i) an expletive in (T)ECs (Icelandic, English).

(ii) a locative PP in Locative Inversion (Branigan 1993, Collins 1997).

(iii) V-raising in contexts with VSO orders (Celtic, Greek; see A\&A 1998 for arguments that in these languages, V-to-I checks the EPP feature).

(iv) a (wh)-phrase in environments of Quotative and Stylistic Inversion.

In exactly these contexts, the SSG applies forcing movement of either the object or the subject to a (layered) specifier of $\mathrm{v}$ and /or $\mathrm{T}$, respectively. One of the two DP arguments must vacate the $\mathrm{vP}$ in order for the derivation to converge, and the derivation converges only if an additional landing site can be provided to host one of the DPs. Crucially, creation of this additional site is independent of the EPP on T. Configurations which escape the effects of the SSG combine three independent parameters that have been proposed in the literature:

(i) the Spec,TP parameter, Bobaljik \& Jonas (1996)

(ii) the doubling parameter, A\&A (1998)

(iii) the object shift parameter, (see Holmberg and Platzack (1995) among others)

The derivations in the languages discussed in A\&A (2001) converge as follows:

(41) Devices satisfying the $S S G$

(i) Icelandic TECs: presence of (an additional) Spec,TP, or an outer Spec,vP.

(ii) Celtic VSO: presence of an additional vP-external specifier (spec,TP) hosting the subject.

(iii) Greek: raising of $\mathrm{X}^{\circ}$ suffices to satisfy the EPP and Case requirements of the subjects (due to the doubling parameter).

(iv) Italian, Catalan: presence of an outer Spec,vP to host the object in VOS.

Interestingly, EPP-related object movement may also lead to improvement in English and in French. Cases in point are cliticization in French (following Kayne 1991; A\&A 1997), and marginal TECs in English. ((43) 
can be taken to involve object movement and v-raising to $\mathrm{T}$; on the latter see Fox and Pesetsky 2004) ${ }^{11}$ :

(42) Tes cours, a quelle occasion les ont manque un grand your course at which occasion them-have been absent from a great nombre d'etudiants?

number of students

(43) ?There entered the room a strange man.

The SSG can thus be formulated as in (44):

(44) At least one category must vacate the vP.

The requirement in (44) is, in turn, linked to the generalized EPP:

(45) Generalized EPP and the SSG

EPP features provide landing sites for arguments escaping the SSG. ${ }^{12}$

The conditions under which such EPP features are assigned on $\mathrm{T}$ and/or $\mathrm{v}$ are subject to parametric variation (see e.g. English vs. Icelandic vs. Italian).

Note, finally, that (45) arises only when the vP domain contains DPs that need to have their Case features valued. Being linked to Case the generalized EPP can - unlike the EPP property of T - not be satisfied by expletives and PPs. The VP data discussed in Collins suggest that a notion of generalized EPP linked to Case is on the right track. The main function of $k o$ consists in introducing an EPP feature into the derivation. $k o$ provides a landing site for one of the nominal objects internal to VP. The structure is only projected to allow the DP object/ nominal PP to raise out of the VP, escaping the verdict of the SSG / MCC.

\footnotetext{
${ }^{11}$ The limited availability of transitive TECs may be due to the special nature of the expletive construction in English, which requires verbs of existence and appearance (Levin \& Rappaport-Hovav 1995). Note also that (43) becomes worse if the participial construction is used and is ungrammatical in negated contexts, a fact strongly reminiscent of conditions in QI (judgements courtesy of Jonny Butler and Thomas McFadden).

${ }^{12}$ (45) is related to the notion of the EPP used in Miyagawa (in press), Chomsky (2005).
} 


\subsection{The SSG in a system with cyclic Agree}

In this final section, we would like to discuss the status of the SSG in a cyclic Agree system, which creates two problems:

The first problem is that A\&A' s (2001) account of the SSG (summarized in section 2.3. above) is incompatible with cyclic Agree where the derivation would proceed as follows:

(46) (i) V is Merged with OBJ yielding the low VP shell

(ii) $\mathrm{v}$ is merged with VP yielding $\mathrm{v}$ '.

(iii) SUBJ is merged with v' yielding vP.

(iv) Agree is established between $\mathrm{v}$ and $\mathrm{OBJ}$, and the structural Case of OBJ is assigned the value ACC, while the phi-features of $\mathrm{v}$ are valued by OBJ. ${ }^{13}$

(v) $\mathrm{T}$ is merged with $\mathrm{vP}$

(vi) Agree is established between T and SUBJ, and the structural Case of OBJ is assigned the value NOM, while the phi-features of $\mathrm{v}$ are valued by SUBJ.

(vii) $\mathrm{v}$ raises to $\mathrm{T}$

In the derivation (46), both arguments enter Case checking relations in a strictly cyclic fashion, as outlined in steps (iv) and (vi). Hence, there is no problem with the Case checking relations established - the vP domain never contains two unvalued Case features since $\mathrm{v}$ and OBJ enter Agree before $\mathrm{T}$ is merged. As a consequence, there is no reason why both the subject and the object cannot remain in-situ. The derivation appears to converge, incorrectly. We conclude that the SSG cannot be (directly) expressed in a system based on cyclic Agree.

The second problem is that the A\&A (2001) cases now differ qualitatively from the Collins (2003) cases in a crucial way. In Collins's cases, the complete head $[\mathrm{v}+\mathrm{a}]$ is inserted as one unit (see (29) above), with two unvalued sets of phi/Case features. By contrast, in A\&A's cases, the complex head is formed syntactically by v-raising to T (step vii in 46), long after valuation of v's phi-features by OBJ and OBJ's Case feature by $v$ (step iv in 46).

In order to (i) re-state the account of A\&A in an Agree based system and (ii) maintain the similarity between the configurations discussed by

${ }^{13}$ It could be that step (iv) precedes step (iii) or, as argued for by Müller 2004, that the relative order between these two steps is a parameter. 
Collins and by A\&A, it is possible to adopt counter-cyclic Agree, as formulated by the 'T-v-Agree Hypothesis' below:

\section{T-v-Agree Hypothesis:}

$\mathrm{v}$ enters Agree with $\mathrm{T}$ and then Case valuation takes place, creating a configuration of Case checking ambiguity ( $\mathrm{v}$ and $\mathrm{T}$ could value the Case of SUB or OBJ).

Under this hypothesis, the Agree relation between the v-T heads emulates the effects of a complex head in the older system.

The question that arises now is the following. Why should Agree between $\mathrm{T}$ and $\mathrm{v}$ precede Case valuation? In order to answer this question we would like to tentatively suggest that an Agree relation between $\mathrm{T}$ and $\mathrm{v}$ can be motivated in at least two ways: (i) Adopting Distributed Morphology, it can be suggested that the vP is categorially underspecified: it can project a clause or be part of a nominalization. In a clause, $T$ provides the categorial specification of vP. ${ }^{14}$ 'Verbal' amounts to 'combining with Tense' (either via head-movement or Agree). (ii) Alternatively, it can be proposed that $\mathrm{T}$ and $\mathrm{v}$ participate in an Agreement relationship which leads to feature valuation for the purposes of the semantic interpretation of Tense (along the lines suggested in Pesetsky \& Torrego 2004). In the new analysis, the relevant steps in the derivation must always be ordered as follows:

(48) (i) First, v Agrees with T, resulting in a Case checking ambiguity/ indeterminacy (what will Agree with what first?).

(ii) EPP provides a guideline for ordering the Agree relations: -If T bears an EPP feature, the first Agree relation involves $T$ and SUB.

-If v bears an EPP feature, the first Agree relation involves $\mathrm{v}$ and OBJ.

(iii) If both $\mathrm{v}$ and $\mathrm{T}$ bear EPP features, Agree proceeds strictly cyclically.

\footnotetext{
${ }^{14}$ For implementations of this idea, see Alexiadou (2001), Bhatt \& Embick (in progress).
} 
On this view, EPP features cancel the ambiguity/indeterminacy configuration. ${ }^{15}$ If our proposal is correct, then SSG effects provide an empirical argument that Agree is - unlike Move - locally counter-cyclic.

\section{Conclusion}

In this paper we attempted to investigate a question raised in section 1: What is the status of the SSG in the grammar? Based on evidence from Indo-European and Khoisian languages we arrived at the following answers:

(i) The SSG is a constraint on multiple case checking which applies in the $\mathrm{vP}$ and the VP domain.

(ii) The EPP functions as a guideline so that a given domain $\mathrm{X}$ can escape the SSG.

A further question ensues once the SSG is embedded in a cyclic Agree system: Does the SSG follow from an independent restriction, such as the ban on complex head formation with two unvalued Case features proposed by A\&A (2001)? If the answer to this question is positive, then SSG effects provide evidence that the Agree relations in the TP domain are locally counter-cyclic, for the reasons discussed in section 5.2.

\section{Appendix: Richards (2004)}

In the recent literature there is a proposal that tries to capture some of the facts discussed in A\&A (2001) within a phase based system, namely Richards (2004). According to Richards (2004), the effects of the SSG can be explained as linearization failures inside the vP-phase. Linearization fails whenever the objects to be linearized in a strong phase are insufficiently distinct.

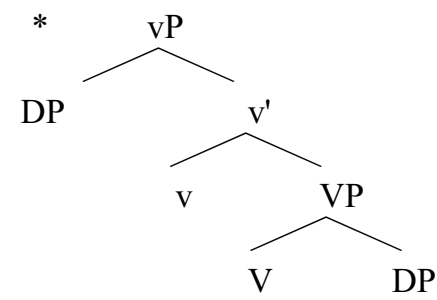

${ }^{15}$ Thanks to Winfried Lechner for discussing this issue and suggesting this option to us. 
Richards proposes that linearization makes reference only to node labels. Moreover, all and only those nodes within a phase must be linearized (Kayne 1994). It follows that syntactic nodes with the same label must not be located too close together in the tree - they need to be separated by a phase boundary, otherwise they cannot be ordered w.r.t. each other. (49) violates this ordering restriction. ${ }^{16}$ Richards observes that this is subcase of a more general ban on multiple adjacent objects similar to the Obligatory Contour Principle (OCP) in phonology (see also Unlike Category Condition of Hoekstra 1984: chap. 2). Richard's account captures the data discussed in A\&A (2001) as well as cases as in (50), initially discussed in Ross (1972):

(50) *The police are stropping drinking on the campus

double-ing

Richards's proposal, however, faces a number of problems:

(i) He cannot account for systematic exceptions to the SSG such as the VSO in Greek/Spanish/Romanian. These languages allow VSO orders with two vP-internal DP arguments as discussed in A\&A (2001).

(ii) Richards cannot explain the data from German and Kilega discussed in section 3 above: in these languages both DP arguments can remain vP-internal, for principled reasons, as we saw. ${ }^{17}$

(iii) Khoisan languages pose a further challenge for Richards' analysis, for the reasons that (a) the arguments subject to the SSG bear distinct category labels (DP, PP) and (b) the domain in which the condition is computed (VP) is not a phase.

(iv) Finally, Richards would predict that multiple series of PP or NP adjuncts are impossible, contrary to fact. ${ }^{18}$

\footnotetext{
${ }^{16}$ It is not clear what the status of v-raising is in Richard's accounts. Note that in his discussion of SI and QI the verb vacates the vP.

${ }^{17} \mathrm{He}$ can account for Kinande if the subject is an NP and the object a DP (see section 3).

${ }^{18}$ There is a further exception involving DP-internal arguments: multiple "of" phrases in nominalizations seem to fall under the same pattern (Alexiadou 2001, Richards 2004):

(i) a. the enemy's destruction of the city

b. the destruction of the city by the enemy

c. *the destruction of the city of the enemy

The contrast between (c) and (b) is crucial. Richards would have to say that one is Case and the other one is P. For A\&A, these examples have a different treatment. Assuming that DPs are not transitive (Alexiadou 2001), the situation we face here
} 


\section{References}

Alexiadou, Artemis. 2001. Functional structure in nominals: nominalization, and ergativity. Amsterdam: John Benjamins.

Alexiadou, Artemis. 1997. Adverb Placement: a Case Study in Antisymmetric Syntax. Amsterdam: John Benjamins.

Alexiadou, Artemis \& Elena Anagnostopoulou. 2001. The subject in situ generalization, and the role of Case in driving computations. Linguistic Inquiry 32: 193-231.

Alexiadou, Artemis \& Elena Anagnostopoulou. 1998. "Parametrizing AGR: Word Order, Verb-movement and EPP checking". Natural Language and Linguistic Theory 16.3: 491-539.

Alexiadou, Artemis \& Elena Anagnostopoulou. 1997. Toward a uniform account of scrambling and clitic doubling. In W. Abraham \& E. van Gelderen (eds.) German: Syntactic Problems- Problematic Syntax. Max Niemeyer Verlag, 142-161.

Alexiadou, Artemis \& Elena Anagnostopoulou. 1996. 'Symmetries, asymmetries and the role of agreement'. Paper presented at the $19^{\text {th }}$ GLOW Colloquium, 17.4.96, Athens, Greece.

Anagnostopoulou, Elena 2003. The syntax of ditransitives. Mouton de Gryuter.

Baker, Mark. 2003. 'Agreement, Dislocation and Partial Configurationality' in A. Carnie, H. Harley, E. Jelinek, and M. Willie (eds.) Formal Approaches to Function in Grammar, Amsterdam: Benjamins, 107-132.

Baker, Mark and Chris Collins. 2005. Linkers and vP Structure. Ms. Rutgers University and New York University. To appear in NLLT.

Benmamoun, Elabbas. 1998. 'Spec-Head Agreement and Overt Case in Arabic'. In D. Adger \& al. (eds) Specifiers: Minimalist Approaches. Oxford University Press, 110-125.

Bhatt, R. \& D. Embick. In progress. Causative Derivations in Hindi. Ms., UMass and UPenn.

Bobaljik, Jonathan \& Andrew Carnie. 1992. 'A Minimalist Approach to some problems of Irish Word Order'. Unpublished manuscript, MIT.

is somehow different. What we have is one head that must value two structural Cases, hence no matter what happens one Case feature remains unvalued. 
Bobaljik, Jonathan \& Diane Jonas. 1996. "Subject Positions and the Role of TP". Linguistic Inquiry 27: 195-236.

Branigan, Phil. 1993. Locative Inversion and the Extended Projection Principle. Doctoral dissertation, MIT.

Cardinaletti, Anna. 1997. 'Agreement and Control in Expletive Constructions: Case makes expletives Agree'. Linguistic Inquiry 28: 521-533.

Cardinaletti, Anna. 1999. 'On Italian Post-verbal Subjects'. Ms., University of Venice.

Carstens, Vicki. 2005. Agree and EPP in Bantou. Natural Language and Linguistic Theory 23: 219-279.

Chomsky, Noam. 1995. The Minimalist Program. Cambridge: MIT Press.

Chomsky, Noam. 2000. Minimalist inquiries: The framework". In: Martin, R./Michaels, D./Uriagereka, J. (ed.) Step by Step. Essays on Minimalist Syntax in Honor of Howard Lasnik, 89-151. Cambridge Mass.: MIT Press.

Chomsky, Noam. 2001. 'Derivation by Phase'. In: Kenstowicz, M. (ed.). Ken Hale: A Life in Language, 1-52. Cambridge: MIT Press.

Chomsky, Noam. 2005. On phases. Ms., MIT.

Collins, Chris. 2003. The internal structure of vP in Ju'hoansi and Hoan. Studia Linguistica 57: 1-25.

Collins, Chris. 1997. Local Economy. MIT Press.

Collins, Chris and Phil Branigan. 1997. 'Quotative Inversion'. Natural Language and Linguistic Theory 15: 1-41.

Collins, Chris and Höskuldur Thrainsson. 1993. 'Object shift in double object constructions and the Theory of Case'. MIT Working Papes in Linguistics 19: 131-174.

Collins, Chris and Höskuldur Thrainsson. 1996. 'VP-internal structure and Object shift in Icelandic'. Linguistic Inquiry 27: 391-444.

Demirdache, Hamida. 1988. 'Nominative NPs in Modern Standard Arabic'. Unpublished manuscript, MIT.

Déprez, Viviane. 1991. 'Two types of Verb Movement in French'. MIT Working Papers in Linguistics 13: 47-85.

Dobrovie-Sorin, Carmen. 1987. Syntaxe du Roumain. These de Doctorat d'Etat. Universite de Paris 7.

Dobrovie-Sorin, Carmen. 1993. The Syntax of Romanian: comparative studies in Romance. Mouton de Gruyter.

Español-Echevarría, Manuel, Manuela Pinto and Maerten de Wind. 1998. 'A uniform analysis of case adjacency in Romanc'. Paper presented at the Workshop on Inversion in Romance, Amsterdam. 
Fanselow, Gisbert. 1996. 'Minimal Link, phi-features, Case and thetalinking'. GLOW Newsletter 36: 30-31.

Fanselow, Gisbert. 2001. "Minimal Link, phi-features, Case and thetachecking'. In Linguistic Inquiry 32.

Fassi-Fehri, Abdelkader. 1993. Issues in the structure of Arabic clauses and words. Kluwer.

Fox, Danny, \& David Pesetsky. 2004. Cyclic Linearization and the typology of movement. Ms., MIT.

Haider, Hubert. 1985. The Case of German. In Studies in German Grammar, J. Toman (ed.) Dordrecht: Foris, 65-101.

Haider, Hubert. 1993. Deutsche Syntax-generativ.Tübingen: Narr.

Haider, Hubert. to appear. How to turn German into Icelandic, and derive OV-VO contrasts. Journal of Comparative Germanic Linguistics 8.

Hoekstra, Teun \& Rene Mulder. 1990. 'Unergatives as Copular Verbs; Locational and Existential Predication'. The Linguistic Review 7: 1-79.

Holmberg, Anders, \& Christer Platzack. 1995. The role of inflection in Scandinavian syntax.. New York, NY: Oxford University Press

Holmberg, Anders and Thorbjörg Hróarsdóttir. 2003. Agreement and movement in Icelandic raising constructions. Lingua 114, 651-673.

Johnson, Kyle. 1991.'Object Positions'. Natural Language and Linguistic Theory 9: 577-636.

Jonas, Diane \& Jonathan Bobaljik. 1993. "Specs for Subjects". MIT Working Papers 18: 59-98.

Iatridou, Sabine \& Anthony Kroch. 1992. "On the Licensing of CPrecursion and its relevance to the Germanic Verb-second Phenomena". Working Papers in Scandinavian Syntax, 50.

Kayne, Richard (1991). Romance Clitics, Verb Movement,and PRO. Linguistic Inquiry 22, 647-686.

Kayne, Richard. 1994. The Antisymmetry of Syntax. MIT Press.

Kayne, Richard and Jean-Yves Pollock. 1975. 'Stylistic Inversion and successive Cyclicity and move NP in French'. Linguistic Inquiry 9: 595-621.

Kayne, Richard and Jean-Yves Pollock. 1998. 'New Thoughts on Stylistic Inversion'. Paper presented at the workshop on Inversion in Romance, Amsterdam.

Levin, Beth and Malka Rappaport. 1995. Unaccusativity: at the SyntaxLexical Semantics Interface. Cambridge: MIT Press.

McCloskey, James. 1991. 'Clause structure, ellipsis and Proper government in Irish'. Lingua 85: 259-302. 
McCloskey, James. 1996a. "Subjects and Subject Positions in Irish". In Bob Borsley and Ian Roberts (eds) The Syntax of Celtic Languages, 241283. Cambridge: Cambridge University Press.

McCloskey, James. 1996b. "On the Scope of Verb-Movement in Irish". Natural Language and Linguistic Theory 14: 47-104.

Miyagawa, Shigeru. In Press. On the EPP. MIT.

Ordoñez, Francisco. 1994. "Post-verbal Asymmetries in Spanish". GLOW Newsletter 32: 40-41.

Ordoñez, Francisco. 1997. Word Order and Clause Structure in Spanish and other Romance languages. Ph. D. dissertation, CUNY.

Richards, Norvin. 2004. A distinctness condition on linearization. Ms, MIT.

Rivero, Maria-Luisa. 1988/1994. "Verb Movement and the Structure of IP in the languages of the Balkans". Natural Language and Linguistic Theory 12: 63-120.

Ross, J.R. 1972. Double -ing. Linguistic Inquiry 3, 6-86.

Sigurðsson, Halldor. 1989. Verbal Syntax and Case in Icelandic. Ph. Dissertation, University of Lund.

Valois, Daniel and F. Dupuis. 1992. 'On the status of verbal traces in French: the case of Stylistic Inversion'. In P. Hirschbühler and K. Koerner (eds) Romance Languages and Modern Liniguistic Theory, John Benjamins, 325-338.

Vikner, Sten. 1994. "Scandinavian Object Shift and West Germanic Scrambling". Studies on Scrambling ed. by Norbert Corver \& Henk van Riemsdijk, 487-517. Berlin: Mouton de Gruyter.

Vikner, Sten. 1995. Verb Movement and Expletive Subjects in the Germanic Languages. Oxford: Oxford University Press.

Watanabe, Akira. 1996. Case Asborption and Wh-Agreement. Kluwer Academic Publishers.

Wurmbrand, Susi. 2004. Licensing Case. Ms., University of Connecticut. 